\title{
Juan Donoso Cortés y Atanazy Raczyński: historia y consecuencias de su amistad
}

\author{
Michal Mencfel ${ }^{1}$ \\ Uniwersytet im. Adama Mickiewicza w Poznaniu \\ Wydział Historyczny, Instytut Historii Sztuki \\ mmencfel@amu.edu.pl
}

RESUMEN: El objeto del presente ensayo es mostrar la historia de la amistad entablada entre Atanazy Raczyński, aristócrata polaco y diplomático prusiano, y Juan Donoso Cortés, político, diplomático y pensador español. Para ello se indican las circunstancias de su encuentro en otoño de 1848 en Madrid y el rápido desarrollo de su relación, que, no obstante, tuvo un comienzo desafortunado y estuvo rodeado de prejuicios iniciales. La idea que aqui se desarrolla es que el fundamento de su amistad, a pesar de la divergencia de caracteres, se basaba en la coincidencia de sus ideas políticas. Dado que el pensamiento de Raczyński, a diferencia del de Donoso Cortés, es poco conocido en España, a él se dedica una parte del artículo, la cual va seguida por un comentario acerca de la influencia que sobre el aristócrata ejercieron las ideas del pensador español, perteneciente a una generación más joven. A modo de ilustración sobre la relación que los unia, el texto se completa con tres cartas no publicadas de Raczyński a Donoso escritas entre 1851 y 1852.

Palabras Clave: Atanazy Raczyński; Juan Donoso Cortés; pensamiento político; historia diplomática; relaciones prusiano-españolas; relaciones polaco-españolas.

\section{Juan Donoso Cortés and Athanaius Raczyński: the history and consequences of their friendship}

ABSTRACT: The subject of the essay is the history of the friendship between the Polish aristocrat and Prussian diplomat Athanasius Raczynski and the Spanish

\footnotetext{
${ }^{1}$ ORCID iD: https://orcid.org/0000-0003-4876-4053.
}

Copyright: (C) 2019 CSIC. Este es un artículo de acceso abierto distribuido bajo los términos de una licencia de uso y distribución Creative Commons Reconocimiento 4.0 Internacional (CC-BY 4.0) 
politician, diplomat and political thinker Juan Donoso Cortés. It considers the circumstances in which they met in Madrid in the autumn of 1848 and how their relationship rapidly developed, despite its unfortunate beginnings and initial prejudices. Developed here is the notion that this friendship, despite differences in character, was based on shared political ideas. Since Raczyński's political thought, unlike that of Donoso Cortés, is not well known in Spain, part of the article is devoted to it, followed by a commentary on the influence which the opinions of Donoso Cortés, who belonged to a younger generation, exerted on Raczyński's way of thinking. Three previously unpublished letters which Raczyński wrote to Donoso Cortés between 1851 and 1852 help illustrate their relationship.

Key words: Atanazy Raczyński; Juan Donoso Cortés; political thought; history of diplomacy; Prussian-Spanish relations; Polish-Spanish relations.

CÓMO CITAR ESTE ARTÍCULO/CITATION: Mencfel, Michał, «Juan Donoso Cortés y Atanazy Raczyński: historia y consecuencias de su amistad», Hispania, 79/261 (Madrid, 2019): 127-156. https://doi.org/10.3989/hispania.2019.005.

Es sabido que Atanazy Raczyński, aristócrata de origen polaco al servicio de la diplomacia del Reino de Prusia, contó entre los amigos más íntimos y los interlocutores más importantes con Juan Donoso Cortés, Marqués de Valdegamas, en los últimos años de su vida. Lo prueba de forma significativa la excelente edición de la correspondencia entre estas dos personalidades del siglo XIX, preparada en el año 1880 por Adhémar d'Antioche². Gracias a esta publicación, las cartas intercambiadas por Donoso y Raczyński —editadas nuevamente a principios del siglo $\mathrm{XX}^{3}$ - constituyen una importante y a menudo provechosa fuente para los estudiosos de la obra del político, diplomático y pensador español. No obstante, el presente ensayo se propone adoptar una perspectiva distinta, una perspectiva biográfica. Su objetivo es presentar las circunstancias en las que se produjo el conocimiento entre el español y el polaco, sus inicios, de hecho difíciles, y su posterior desarrollo, hasta llegar a una amistad íntima. Señalaré también la importancia que para la reflexión política de Raczyński tuvo el encuentro con la personalidad y la obra de Donoso Cortés.

Mi análisis está basado en amplias fuentes primarias, en su mayoría no publicadas, y en particular en el monumental diario de Atanazy Raczyński, custodiado en forma de manuscrito en una colección privada de Londres (en

\footnotetext{
2 ANTIOCHE, 1880.

${ }^{3}$ DONOSO CORTÉS, 1904: 635-728.
}

Hispania, 2019, vol. LXXIX, nº 261, enero-abril, págs. 127-156, ISSN: 0018-2141, e-ISSN: 1988-8368 
adelante Diario o Dziennik $)^{4}$; y en su correspondencia diplomática y privada guardada en los archivos del Geheimes Staatsarchiv Preußischer Kulturbesitz en Berlín (en adelante GStA) .

Se completa este texto con tres cartas de Atanazy Raczyński a Donoso Cortés, incluidas en el Diario. Las cartas pueden constituir una fuente interesante para los estudiosos de la vida y obra del autor español.

\section{II}

Atanazy Raczyński (fig. 1) nació el 2 de mayo de 1788 en Poznań, la capital de la Región de Wielkopolska que constituía entonces parte del Reino de Polonia, todavía independiente (en 1793 a consecuencia de la llamada segunda división de Polonia, Wielkopolska fue incluida en el Reino de Prusia) ${ }^{6}$. Fue el segundo hijo del general Filip Raczyński y de Michalina de Raczyński, hija de

${ }^{4}$ El manuscrito del Diario forma parte de la colección de doña Katarzyna Raczyńska en Londres. Se compone de 12 volúmenes de gran tamaño, en total más de siete mil páginas. Incluye las memorias de su infancia y los apuntes corrientes de los años 1808-1866. No es una copia autógrafa sino una copia manuscrita redactada por orden de Raczyński a caballo entre las décadas cuarenta y cincuenta del siglo XIX, y posteriormente completado a finales de los sesenta. Ha sido copiado mayoritariamente por los secretarios de Raczyński, incluye también sus notas y comentarios manuscritos, así como dibujos y acuarelas de su autoría. Después de la muerte de Raczyński, de conformidad con la voluntad del difunto expresada en el codicilo de su testamento del 15 de septiembre de 1869, la copia, junto con el paquete de su correspondencia de las décadas cuarenta y cincuenta, se depositó en manos de su amigo, el diplomático y estadista saboyano, conde Alphonse de Brotty d'Antioche, residente en la localidad de Nernier junto al Lago de Ginebra. En Nernier el documento fue guardado hasta el año 1933 en el que Edward Bernard Raczyński, el primo bisnieto de Atanazy, en aquel entonces delegado del gobierno de la República de Polonia en la Socieda de Naciones en Ginebra, lo compró a los herederos de d'Antioche. Por sus gestiones el Diario llegó posteriormente a Londres. Hasta la fecha solamente han sido publicados algunos fragmentos del Diario: los apuntes del año 1824 hechos en París, publicados en 1893 por el hijo de Alphonse d'Antioche, Adhémar (ANTIOCHE, 1893), así como las memorias de la infancia y una selección de apuntes de los años 18081818, en traducción al alemán y redactados por Joseph Raczyński (RACZYŃSKI, 1984).

5 III, HA Ministerium der auswärtigen Angelegenheiten I, Nr. 7031, Preußische diplomatische Vertretung in Spanien, Apr. 1848-Sept. 1856; Nr. 7106-7110, Schriftwechsel mit der preußischen diplomatischen Vertretung in Madrid, Mai 1848-Dez. 1852; I. HA Rep. 81 Madrid: Gesandtschaft Madrid nach 1807: Nr. 15, Korrespondenz mit dem Ministerium der auswärtigen Angelegenheiten, 1848-1857, Nr. 23, Beurlaubung des Gesandten Grafen von Raczynski, 1850-1851, Nr. 24, Anfragen Raczynskis an en Geh. Rath Hahn zu Berlin über persönliche Angelegenheiten, 1850-1852, Nr. 52, Korrespondenz mit dem spanischen Hofe, Ministerium und Behörden, 1848-1857; VI. HA N1 Karl Friedrich von Savigny, Nr. 208: Briefe des Grafen Raczynski an K. F. von Savigny, 1841-1849.

${ }^{6}$ Las informaciones biográficas principales relativas a Atanazy Raczyński: DONOP, 1888. KIENIEWICZ, 1986. MENCFEL, 2016. 
un influyente mariscal de la corte real, Kazimierz Raczyński, creador de la alta posición económica y política de esta estirpe. Después de una muerte prematura de los padres - la madre falleció en 1790 y el padre en 1804- precisamente Kazimierz Raczyński fue nombrado tutor legal de Atanazy y fue quien influyó decisivamente en la formación intelectual y, en gran medida, también en la personalidad de su nieto.

Atanazy Raczyński, cuidadosamente formado (primero en su casa de Rogalin y después en la universidad de Fráncfort del Óder, así como con maestros privados en Berlín y Dresde), desde una juventud temprana fue preparado para el servicio público. Miembro de una familia pudiente y con potencial intelectual y una personalidad eminentes, su vida adulta la dedicó sobre todo a dos grandes pasiones: la política y — lo que no nos va a interesar aquí — , el arte. El escenario en el que realizaba ambas inclinaciones fue sobre todo Berlín, donde fijó su domicilio permanente a principios de los años treinta y donde vivió hasta su muerte, acaecida el 21 de agosto de 1874.

Se dedicaba a la política de forma profesional y práctica ya que ejerció de diplomático, primero de Sajonia (entre 1813-1815) y después de Prusia (18301852), fue delegado de las Cortes Provinciales de Poznań (Provinziallandtag des Großherzogtums Posen, a partir de año 1827) y miembro hereditario de la Casa de los Señores de Prusia (Das Preussische Herrenhaus) (a partir del año 1854); pero también de forma teórica ya que elaboró para sí una refinada y coherente doctrina política de carácter conservador categórico.

En 1830, después de varios años de esfuerzos, Raczyński entró en el cuerpo diplomático prusiano y fue nombrado diputado extraordinario y ministro plenipotenciario (ausserordentlicher Gesandter und bevollmächtiger Minister) del Reino de Prusia en la corte danesa. Fue el puesto de máximo rango en las estructuras diplomáticas prusianas ${ }^{8}$. Ejerció esta función durante cuatro años. En 1842, volvió al servicio público después de un intervalo de un par de años, ocupando las representaciones diplomáticas primero en Lisboa (1842-1848) y luego en Madrid (1848-1852). Las funciones ejercidas en las estructuras diplomáticas garantizaron a Raczyński una posición de responsabilidad tanto en los círculos de la administración estatal prusiana como entre la élite diplomática europea. Unas vastas relaciones en las esferas políticas, un estupendo conocimiento de cuestiones europeas, una visión perspicaz, unas aptitudes analíticas $y$, finalmente, un estilo literario atractivo, un poco aforístico, otorgaron al

${ }^{7}$ La actividad de Raczyński en el campo de las artes, su labor de coleccionista, mecenas y escritor, ha sido estudiada por varios autores. Véanse, entre otros: BÖRSCH-SUPAN, 1975. DANILEWICZ-ZIELIŃSKA, 1981. BÜTTNER, 1992. GRAUER, 2004. GAEHTGENS, 2006. LABUDA, MENCFEL y SUCHOCKI, 2010. DESWARTE-ROSA, 2011. KAISER, 2017.

${ }^{8}$ Sobre la organización del servicio diplomático prusiano en el siglo XIX, véase: GRYPPA, 2008.

Hispania, 2019, vol. LXXIX, nº 261, enero-abril, págs. 127-156, ISSN: 0018-2141, e-ISSN: 1988-8368

https://doi.org/10.3989/hispania.2019.005 
Figura 1. Federico Madrazo y Kunz, Retrato de Atanazy Raczyński, 1850

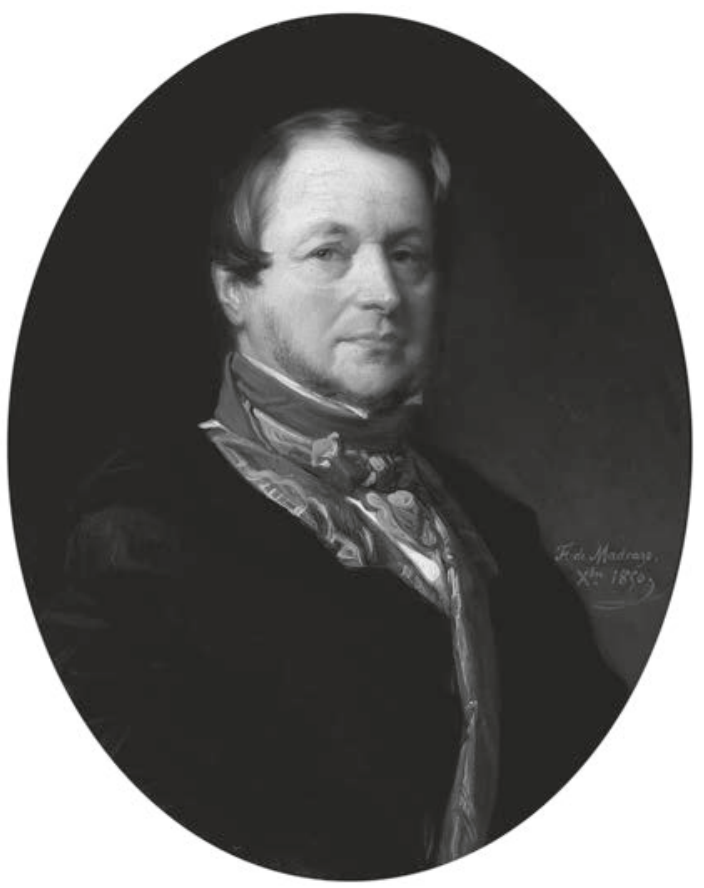

Fundación Raczyński, Museo Nacional de Poznań, sign. MNP FR 528.

concepto político de Raczyński valores que le permitieron situarse en la misma línea que los representantes más eminentes del pensamiento conservador europeo. Todo lo dicho hasta el momento nos autoriza a considerarle quizá no del todo influyente, pero sí muy activo, dotado de sentido crítico y, al mismo tiempo comentarista de la vida política o, más aún, pública, hechos que le situan entre las importantes personalidades políticas del siglo XIX.

\section{III}

A Madrid Raczyński llegó directamente desde su representación diplomática anterior en Lisboa. Las circunstancias que rodearon su nombramiento como representante del Reino de Prusia en la corte española fueron especiales y dignas de recordar.

El contexto principal de este nombramiento lo constituyen los acontecimientos relacionados con la Revolución de 1848 que se extendía en los países alemanes, sobre todo en Prusia. En cuanto Raczyński supo de los desórdenes 
Figura 2. Atanazy Raczyński, Panorama de Madrid, julio 1852

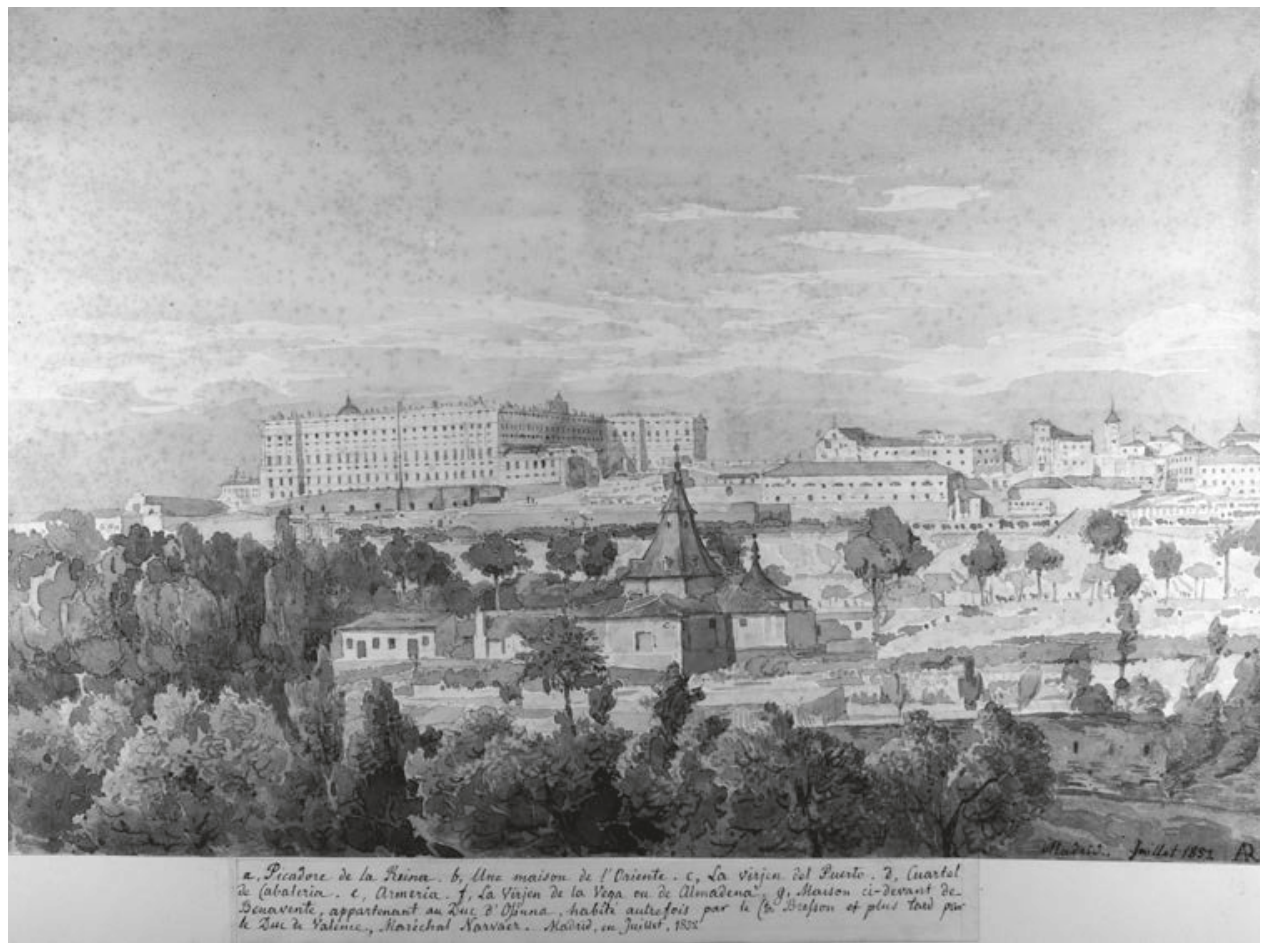

Acuarela, colección privada.

que habían estallado en la primavera de 1848 en Berlínº, envió el día 2 de abril una carta llena de dramatismo al recién nombrado ministro de Asuntos Exteriores del Reino de Prusia, barón Heinrich Alexander von Arnim pidiendo que se le destituyera de los deberes oficiales. En la carta escribió: «He llegado a la edad de sesenta años y soy ya demasiado viejo para poder alistarme al

${ }^{9}$ El The Times londinense, que constituía para Raczyński la principal fuente de información sobre los acontecimientos en Alemania, comunicaba en el número del 16 de marzo que: «Germany is now thoroughly roused. From Hamburg to Vienna, from Aix-le-Chapelle to Königsberg, she petitions with one voice for constitutional reform and a united representation of her whole race. [...][In Berlin] The King has promised freedom of the press, and a convocation of the States-General at the earliest moment. So far so good. I believe he will not stop there, and that he will proceed onward in the cause of Reform» (The Times, Thursday, March 16, 1848, s. 6). Unos días después el Diario relataba desde la capital de Prusia: «The populace there are stated to be still in a state of turbulence, if not actual insurrection. On Wednesday night there had been a very serious collision between the people and the military, the students being ver prominent among the people acting as their leaders, and bearing the brunt of the conflict. Ten deaths resulted, and there were upwards of a hundred wounded», (The Times, Monday, March 20, 1848, s. 5). 
movimiento que requiere fuerzas nuevas. Me permito por lo tanto pedirle humildemente a Vuestra Excelencia que deposite a los pies de mi más bondadosa Majestad el Rey la solicitud llena de respeto y sumisión de mi destitución del servicio estatal. Que el más benévolo de todos los Príncipes consiga detener esta tormenta horrorosa que trae consigo la destrucción y que se ha extendido en Prusia, Alemania y toda Europa y llegue a reestablecer a su pueblo la paz, la calma, el orden y la seguridad personal y de propiedad de las que disfrutaba Prusia tantos largos años. [...] Debo expresar en primer lugar mi decisión de retirarme totalmente de la vida pública y de no participar más en la política interior o exterior de mi país o de ningún otro país» ${ }^{10}$.

Los acontecimientos revolucionarios en Berlín, las demandas de liberalización de la vida política y las concesiones de Federico Guillermo IV a su favor significaban en la opinión de Raczyński la revelación y el triunfo de las fuerzas enemigas, destructivas y revolucionarias en el país que hasta entonces constituía uno de los últimos y seguramente el más importante centro de resistencia contra ellas. En este contexto, la petición de Raczyński de su destitución era una maniobra drástica, pero indispensable. La apuesta era la fidelidad a los ideales profesados, cuya materialización, quizá no siempre perfecta, era Prusia. La presencia de los liberales en la vida política de Prusia y su inevitable así pensaba Raczyński - democratización provocaron que dejase de ver allí su sitio.

A pesar de que la solicitud de Raczyński llegó a ser comprendida por el monarca tal y como le aseguraba Arnim en las cartas, y aún más llegó a «conmoverse profundamente», el conde no atendió la destitución deseada. Al contrario, «precisamente en estos tiempos fatales, Su Majestad le concede a Usted el mayor valor y expresa su deseo persistente de que continúe prestando su servicio al Rey y a la patria en un puesto nuevo, prestigioso e importante» ${ }^{11}$. Este

10 «Ich habe mein sechzigstes Jahr erreicht und bin nun zu alt, um mich einer Bewegung anzuschließen, welche frischere Kräfte erfordert. Ich beehre mich daher, Eur Excellenz ganz gehorsamst zu ersuchen, meine ehrfurchtsvolle und unterthänigster Bitte wegen meiner Entlassung aus dem Staatsdienste meinem allergnädigsten Könige und Herrn zu Füssen zu legen. Möge es dem hochherzigsten aller Fürsten gelingen, das scheußliche Gewitter, welches über Preußen, über Deutschland, über ganz Europa sich entladen hat, in seinen versehrenden Folgen auszufalten und seinem Volke Frieden, Ruhe, Ordnung und Sicherheit der Personen und des Eigenstands, welche Preußen so lange genoßen hat, wieder zu geben. [...] Ich muß hier zugleich meinem Entschluß aussprechen, aus dem öffentlichen Leben mich ganz zurückzuziehen und an der inneren und außeren Politik meines oder irgend eines Landes ferner keinen Antheil zu nehmen», de la carta de A. Raczyński al ministro Heinrich Alexandr von Arnim del 2 de abril de 1848, GStA, III, HA, Ministerium der auswärtigen Angelegenheiten I, Nr. 6210.

11 «S.[eine] M.[ajestät] sind von Ihrem Entschlusse barmherzlich berührt worden und ebengleich S.M. die Bestimmungsgründe desselben zu mißbilligen weit entfernt sind, vielmehr sie noch ihrem wahren, inneren Werthe zu würdigen wissen, so hatten Allers. Dieselben 
nuevo y prestigioso puesto fue la representación diplomática en Madrid que Raczyński deseaba para sí desde hacía varios años. Todavía como representante en Lisboa, Raczyński sondeó varias veces la posibilidad de su traslado a España $^{12}$. Raczyński no pudo no subordinarse a la voluntad real por la mera razón de que se trataba precisamente de la voluntad real. La objeción contra el deseo del soberano no cabía en absoluto en el horizonte moral de un aristócrata cuyos principios fundamentales eran la lealtad y la incondicional obediencia a la voluntad del rey. Además en el tormentoso año de 1848, la negativa del cumplimiento de la voluntad real adquiriría un significado adicional e inquietante. Pero había también otras razones, sobre todo dictadas por la ambición, por las que la propuesta de tomar la representación diplomática en España recibió la aprobación de Atanazy. Era la primera vez en su carrera que se le le ofrecía tan alto puesto diplomático y sin tener que presentar solicitudes, escribir varias peticiones, esperar de forma humillante... Es más que una figura retórica, la confesión de Raczyński de que la carta real fue para él fuente de una fuerte conmoción que le «llevó a las lágrimas» $\mathrm{y}$, tal como confesaba a uno de los amigos, simplemente no pudo rechazar la amable petición del rey ${ }^{13}$. Además se trataba de una representación diplomática de mayor importancia que las que había dirigido hasta ahora en Copenhague o Lisboa. Raczyński sabía evaluar realmente su posición dentro de las estructuras estatales y tenía una dolorosa conciencia de que las representaciones diplomáticas más importantes: París, Londres, Viena o Petersburgo se situaban - entre otras, a causa de su origen polaco $^{14}$ - fuera de su alcance: «Las cuatro grandes misiones exigen una con-

sich doch nicht entschließen mögen, Sich Ihrer ferneren Dienste zu berauben. S. M. langen auf dieselben gerade in der jetzigen verhängnisvollen Zeit den größten Werth und haben den dringenden Wunsch, daß Eur Allerst. Ihnen und dem Vaterlande in einer neuen ehrenvollen und wichtigen Stellung auch ferner Ihre Dienste widmen wollen», de la carta de Heinrich Alexandr von Arnim a A. Raczyński del 26 de abril 1848, GStA, III, HA Ministerium der auswärtigen Angelegenheiten I Nr. 7031. Véase también: ANTIOCHE, 1880: 4-6.

12 Raczyński mostraba interés por el puesto en Madrid desde sus primeros trámites de la admisión a las estructuras dipolomáticas. Ya en 1824 escribía en la carta al rey Federico Guillermo III: «Le poste de Madrid se trouvant vacant, c'est plus particulièrement sur calui-là que j'ose porter mes vues» (carta del 25 de septiembre de 1824 en: Politisches Archiv des Auswärtigen Amtes, Berlin, Acta betr. die persönlichen Angelegenheiten des Grafen von Raczinsky, 011609). Declaraciones parecidas aparecen muchas veces en la correspondencia de Raczyński hasta mediados de los años 40 y también después de tomar el puesto en Portugal (véase por ejemplo la carta al ministro de Asuntos Exteriores Ulrich Heinrich Wilhelm von Bülow, del 25 de enero de 1844).

13 Véase la carta de Raczyński a Karl Friedrich von Savigny, fechada en Madrid el 16 de junio de 1848, en GStA, Berlin, VI, HA N1 Karl Friedrich von Savigny, n. ${ }^{\circ} 208$.

${ }^{14}$ En su Diario, Raczyński varias veces expresaba — no sin razón — su impresión de que el origen polaco constituía un obstáculo en el camino a los puestos más altos en la estructura del estado prusiano. Efectivamente fueron muy pocos los polacos que lograron una carrera política considerable en el Reino de Prusia. Aunque en ello influyeron también otras circunstancias 
fianza enorme de la cual, como parece, yo no soy digno», escribía todavía en el año $1836^{15}$. La misión en Madrid pertenecía a los más prestigiosos puestos con los que podía contar.

Figura 3. Juan Noguera, Plano de Madrid 1849

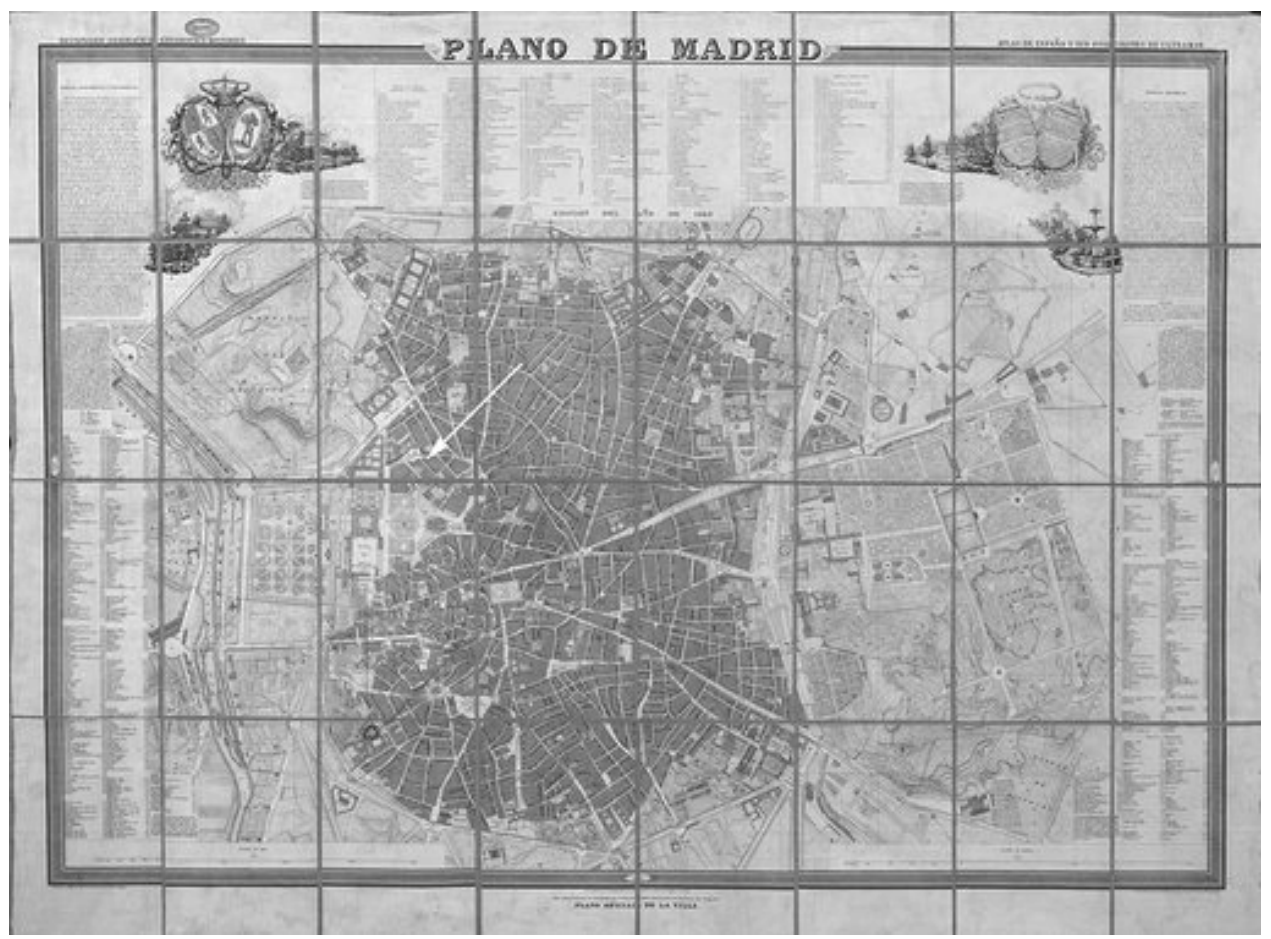

Biblioteca Nacional de España, sign. Mr/34/1207.

Con la flecha se ha marcado el lugar de residencia de Raczyński.

De la capital portuguesa Raczyński partió el 23 de mayo del año 1848 en un barco de vapor a Cádiz y después, por vía terrestre, a Sevilla y Córdoba. Desde el principio fue recibido en España con grandes honores. En Cádiz, aparte del gobernador de la ciudad, le esperaban la orquesta militar y la guardia real: une

como, por ejemplo, la presión de la opinión pública polaca adversa a que los polacos participasen en la vida política de un país opresor que conducía a una autoexclusión, sin embargo la aversión de la administración prusiana seguía siendo una condición decisiva.

15 «Les quatre grandes missions supposent une grande confiance qu'on parait n'avoir pas en moi», Diario, 27 de enero de 1836. 
Figura 4. Atanazy Raczyński, Calle de las Rejas, Embajada de Prusia en Madrid, Madrid, 17 de mayo de 1852.

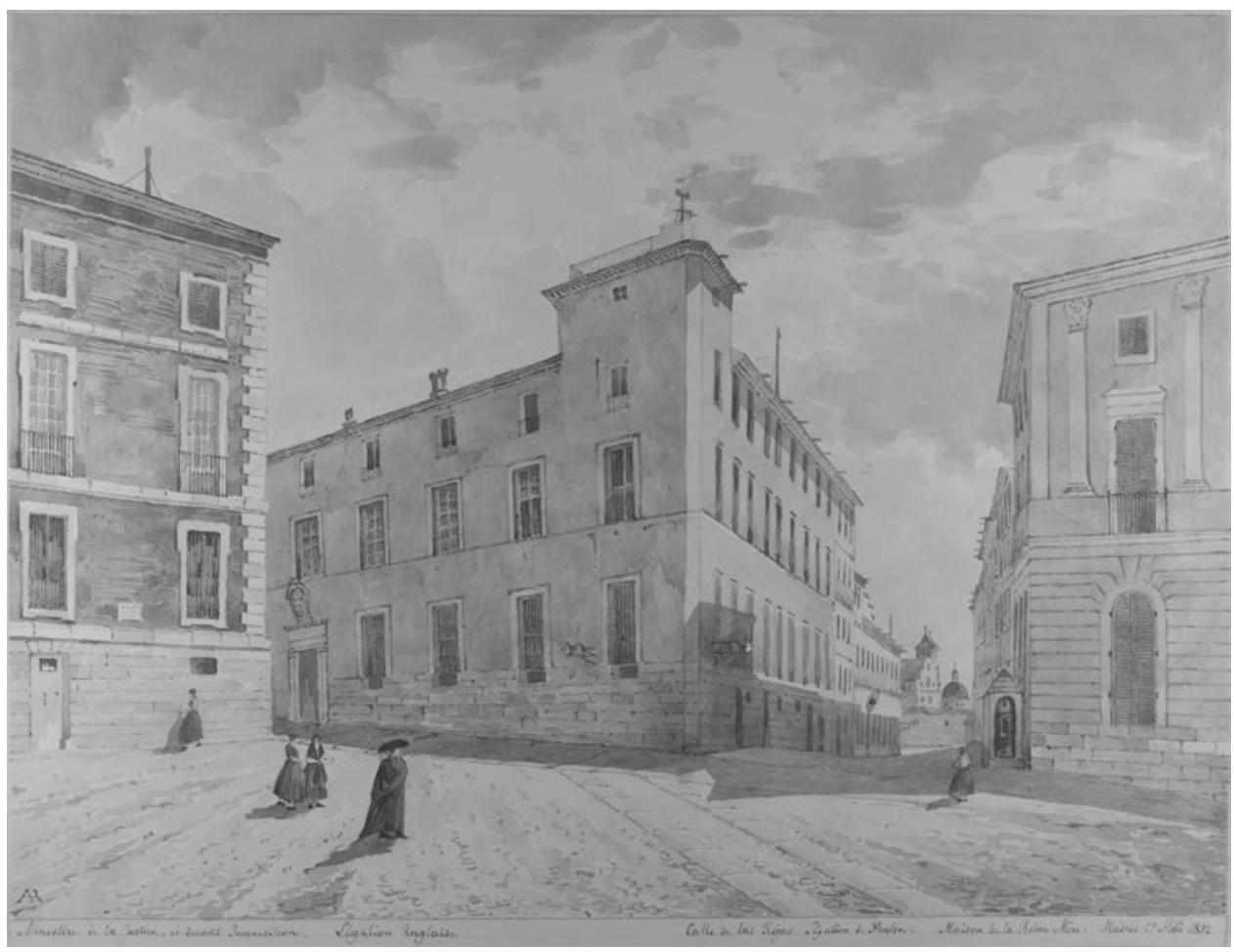

Acuarela, colección privada.

garde de 50 hommes avec drapeau et musique en tête ${ }^{16}$. A la capital del país Raczyński llegó el 31 de mayo de 1848 por la tarde (fig. 2). Se alojó, como relacionaban los diarios locales, en un apartamento de la planta segunda del hotel más representativo de Madrid, en la recién construida Casa de Cordero ${ }^{17}$. Después alquiló un apartamento en la calle Mayor y seguidamente dos casas en la calle de las Rejas. En la segunda de ellas, en la calle de las Rejas número 2, situada precisamente en frente del palacio de la reina madre María Cristina vivió desde junio de 1849 hasta el final de su servicio en España, es decir hasta el 28 de agosto de 1852 (fig. 3, fig. 4). El día 2 de junio por la tarde fue recibido por la reina en una audiencia especial. Dos semanas después, el presidente del

${ }^{16}$ De la carta de Raczyński al ministro Heinrich Alexandr von Arnim del 26 de mayo de 1848, GStA, III, HA Ministerium der auswärtigen Angelegenheiten I, n. ${ }^{\circ} 7106$.

${ }_{17}$ La Esperanza, 1196, viernes 9 de junio de 1848: 4. El Heraldo, 1, 845, 3 de junio de 1848: 2. El Popular, 613, sábado, 3 de junio de 1848: 2. 
Consejo de Ministros, Ramón María Narváez, organizó un gran convite en honor del representante de Prusia — un banquet splendide - en el que participaron varias figuras importantes de la vida política, incluido el esposo de la reina, Agustín Fernando Muñoz y Sánchez, duque de Riánsares; el ministro de Asuntos Exteriores, Carlos Martínez de Irujo, duque de Sotomayor; el presidente del senado, Manuel Pando Fernández de Pindeo, marqués de Miraflores; el capitán general de Madrid, Juan González de la Pezuela y Ceballos y todos los ministros: «en total 34 personas a la mesa» ${ }^{18}$.

No fue ésta la primera visita de Raczyński a España, ya que tres años antes, en julio de 1845, había pasado, de camino, de Berlín a Lisboa. Conoció entonces Barcelona, Valencia, Málaga y Sevilla, pero se trataba de unas visitas cortas que traía sólo un conocimiento superficial de dichas ciudades; además el principal objeto de interés de Raczyński era entonces el arte español ${ }^{19}$.

\section{IV}

El primer contacto con España y su vida política en el año 1848 fue muy satisfactorio para Raczyński a pesar de que iba aquí lleno de temores. Todavía el 26 de mayo, de camino a Madrid, escribía a Heinrich Alexandr von Arnim: «Si miramos hacia donde el destino conduce a este país, podemos dudar de su futuro $\rangle^{20}$. Mientras tanto, en la capital predominaba el ambiente monárquico, antiliberal y anticonstitucional, lo cual Raczyński constató con sorpresa y con alivio ya que tales convicciones le eran cercanas. Ya el 3 de junio escribió en un informe oficial al rey: «No hay otro país en que la gente hablase sobre la libertad con menos respeto que en España: aquí la gente conoce el significado de este concepto y está convencida de que el constitucionalismo moderno es un malabarismo, una imposibilidad y una gran amenaza para la seguridad del país y para el trabajo del pueblo. Como escucho por aquí, han quedado en España ya muy pocos tales políticos tontos e ingenuos. Únicamente los ambiciosos sin

${ }^{18}$ De un informe confidencial al ministro Heinrich Alexandr von Arnim (Rapport confidentiel no. 1) del 16-17 de junio de 1848, GStA, III, HA Ministerium der auswärtigen Angelegenheiten I, n. ${ }^{\circ} 7107$.

${ }_{19}$ El resultado literario de este interés fue un capítulo en el libro de Raczyński sobre el arte portugués dedicado a la herencia artística de España (Les arts en Portugal), véase RACZYŃSKI, 1846: 487-524.

${ }^{20}$ «Quand on voit à quoi tient le sort de ce pays-ci, il n'est pas possible d'avenir confiance dans son avenir... surtout quand on considère que les pays jadis les mieux gouvernés et les plus fortunés se couvrent de sang et de ruines par le seul effet de quelques préoccupations et d'une infinité de mensonges», de la carta de Raczyński do Heinrich Alexandr von Arnim del 25 de mayo de 1848 r., GStA, III, HA Ministerium der auswärtigen Angelegenheiten I, n. 7106 . 
puestos aman la libertad y la constitución, tanto más ferviente y sinceramente, cuanto menos es una emoción desinteresada. Entre ellos hay muchos que nunca han renunciado al calificativo de progresistas, pero hay también otros que en tiempos anteriores ya habían cambiado de juicios $»^{21}$.

A lo largo de su estancia y tras una observación más detallada del país, debió revisar sus dictámenes. Los conflictos y los desórdenes que contemplaba en España durante su estancia en Madrid le inspiraban unos pronósticos muy pesimistas. Miraba con temor el desarrollo de la situación política y se inclinaba a prever la vuelta al ambiente liberal. Después de pasar tres años en la capital española escribía en un informe al rey el día 8 de abril de 1851: «Lo que está pasando aquí ahora despierta mi gran inquietud. En un futuro próximo las intrigas de los progresistas y la política de lord Palmerston manifestarán una convergencia perfecta. La apuesta en este juego la constituyen el orden, la tranquilidad, el progreso material de los últimos años. Los progresistas ni siquiera esconden su gran alegría. [...] Es igual si el gobierno se basa en ellos o si les domina ya que asimismo llegará a ser su víctima. No temo menos a los diputados independientes aunque les aprecio más. Las pasiones y la locura se desencadenarán mayores que en cualquier otro momento. O habrá que recurrir una vez más a Narváez, o el Estado será abatido por las olas y su suerte dependerá tan sólo de una casualidad. ¡Y la corte, y los generales, y la Francia revolucionaria, y la situación insegura del resto de Europa...! Tan lejos como alcanza mi vista, veo sólo amenazas $\rangle^{22}$. Su abatimiento lo producían no solamente los acontecimientos políticos, sino también una creciente convicción de que se

${ }^{21}$ «Il n’y a pas de pays où les gens sensés parlent avec moins de respect de la liberté qu’en Espagne: ils connaissent la valeur de cette notion; ils sont convaincus que le constitutionalisme moderne est une jonglerie, une impossibilité, un danger incommensurable pour la partie saine et laborieuse du peuple. Il n'a plus, à ce que j'entende dire, que fort peu de niais et de gobe-mouches politiques en Espagne. Il n'y a que les ambitieux sans place qui portent à la liberté et à la constitution un amour d'autant plus vrai et ardent qu'il n'est rien moins que désintéressé. Il y en a beaucoup parmi eux qui n'ont jamais abjuré le titre de progressistes, mais il y en a d'autres qui ont déjà, à différentes époques, changé de couleur», informe del 3 de junio de 1848, GStA, Berlín, III, HA Ministerium der auswärtigen Angelegenheiten I, n. ${ }^{\circ} 7106$.

${ }^{22}$ «Ce qui se passe maintenant ici m'inspire de vives inquiétudes. Dans un prochain avenir, les menées des progressistes et la politique de Lord Palmerston montreront leur imprescriptible coïncidence. L'ordre, la tranquillité, le progrès matériel des dernières années sont en jeu. Les progressistes ne dissimulent pas leur joie. On les verra envahir les banes de la gauche dans le congrès. Que le Gouvernement s'appuie sur eux, ou qu'il les combatte, il en sera victime. Je ne crains pas moins les députés indépendants, quoique je les estime davantage. Les passions et la folie vont se déchainer plus furieuse que jamais. Ou on devra avoir recours une autre fois à Narvaez, ou le vaisseau de l'état sera battu par les flots et son sort ne dépendra plus que du hasard. Et la cour, et les généraux et la France révolutionnaire, et la situation incertaine du reste de l'Europe !... Quelque part que mes regards se portent, je ne vois que dangers», informe del 8 de abril de 1851, GStA, Berlin, III, HA Ministerium der auswärtigen Angelegenheiten I, n. ${ }^{\circ} 7109$. 
estaba desarrollando una crisis general de la cultura europea. En las cartas privadas de esta época Raczyński dibujaba una imagen muy amarga de su actualidad. No se deshizo del todo de su fe en el futuro gracias a su profunda confianza en la Providencia, pero le atemorizaba la maldad que arrastraban tras de sí la hipocresía, la soberbia, el desprecio y el amor propio. Estas opiniones las expresó en la carta a Juan Donoso Cortés del 29 de diciembre de $1849^{23}$. El español fue ya en aquel momento uno de los más importantes corresponsales de Raczyński.

\section{V}

Raczyński conoció a Juan Donoso Cortés un par de meses después de su llegada a Madrid, a finales del otoño del año 1848. Sin embargo, los principios de su relación no fueron prometedores. Raczyński se interesó por la persona de Donoso Cortés cuando se planteó su nombramiento al puesto de embajador de España en la corte prusiana en Berlín ${ }^{24}$. Esta elección no fue del agrado de Raczyński por tres motivos, principalmente.

En primer lugar, se sintió disgustado por la manera en la que se enteró del nombramiento de Donoso Cortés, la nota de prensa publicada en El Popular ${ }^{25}$. Sin cuestionar la total autonomía de los estados a la hora de designar a sus propios diplomáticos, Raczyński creía que era de buen gusto consultarlo con el representante del gobierno del país al que iba a ser enviado el representante. Poco después de su llegada a Madrid, al conocer que se pensaba en la candidatura de Donoso Cortés, presentó una protesta oficial y una petición de que se nombrara un diplomático distinto. Mientras tanto escribía a su superior en Berlín, «esta opinión no ha sido tomada en consideración en absoluto» (Cet avis n'a pas été pris en considération) y con ello se habían violado, según Raczyński, las normas del juego diplomático ${ }^{26}$.

Por otro lado, Raczyński consideró un desprecio el hecho de que, simultáneamente con la candidatura de Donoso Cortés a representante de España en el Reino de Prusia, se hubiese anunciado el nombramiento de Mariano Nicolás Álvarez de las Asturias-Bohórques, duque de Gor, para el puesto de embajador en Viena. Raczyński consideraba que el duque de Gor por su espléndido origen familiar, las cualidades de carácter y una posición fuerte en la corte española era «uno de los más eminentes miembros de la grandeza española» que ocupaba

\footnotetext{
23 ANTIOCHE, 1880: 28-30.

24 BLED, 1973.

${ }^{25}$ El Popular, domingo, 5 de noviembre de 1848, suplemento: 1.

${ }^{26}$ La carta de Raczyński al ministro August Heinrich Hermann von Dönhoff del 5 de noviembre de 1848, GStA, III, HA Ministerium der auswärtigen Angelegenheiten I, n. ${ }^{\circ} 7106$.
} 
junto con su esposa «un lugar preeminente, si no el principal, entre las élites aristocráticas» del país. Mientras que Donoso Cortés pertenecía, a los ojos de Raczyński, a «una categoría totalmente diferente». De ahí que escribiese a Berlín: «Todos están sorprendidos al ver estos dos apellidos uno al lado del otro en relación con un mismo asunto». Destinar al duque de Gor a Viena y a Donoso Cortés a Berlín significaba el deseo de favorecer a Austria y despreciar a Prusia, lo cual en Raczyński «como súbdito del rey y ciudadano de Prusia», muy sensible a las cuestiones de prestigio, produjo «una impresión desagradable» ${ }^{27}$.

Finalmente, a Raczyński le indisponían con Donoso Cortés las opiniones que había oído sobre él. Raczyński no le conocía personalmente y, como subrayaba en diversas ocasiones, no sentía ningún «prejuicio personal» con respecto a él - Je n'ai aucune prévention personnelle contre lui- sin embargo, no se fiaba de las garantías que el ministro Pidal, el presidente Narváez o incluso la misma reina María Cristina le daban sobre sus valores y sus competencias. En la carta al ministro de Asuntos Exteriores de Prusia, Dönhoff, del 8 de noviembre de 1848, basándose en los rumores que había oído, presentó al español como partidario de la constitución, charlatán político vano y casi ridículo, lo cual cubría con una erudición y una elocuencia eminente: «El señor Donoso Cortés no vale demasiado, es un picapleitos de Badajoz, partidario del constitucionalismo doctrinario, gran hablador que gracias al talento para lugares comunes recibió el apodo de Quiquiriquí. Tiene conocimientos vastos, es escritor. Su ocupación predilecta es la filosofía de la historia. A su personaje está atada la ridiculez» ${ }^{28}$.

${ }^{27}$ «Je dois faire remarquer á Votre Excellence que le Duc de Gor est par sa naissance et par ses qualités éminents un des membres les plus distingués de la Grandesse d'Espagne, que la Duchesse comme Grand Maitresse occupe la première place á la cour, que la réputation du mari et de la femme est une des plus pures qu'il y ait en Espagne. Ils occupent tous deux parmi l'élite de l'aristocratie une des premières places, si non la première. Pour ce qui est de Mr. Donoso Cortès, c'est tellement une autre catégorie, que tout le monde a du s'étonner de voir ces deux noms ensemble á propos d'une même chose». «Tout ceci n'empêche pas que la nomination simultanée de Mr. Donoso Cortès pour Berlin, et celle du Duc de Gor pour Vienne ne m'ait fait l'effet d'un contraste, et que je n'en aie reçu comme serviteur du Roi et comme Prussien une impression pénible», de la carta de A. Raczyński a August Heinrich Hermann von Dönhoff (Rapport politique, n. $^{\circ}$ 37) del 8 de noviembre de 1848 r., GStA, III, HA Ministerium der auswärtigen Angelegenheiten I, n. ${ }^{\circ}$ 7106. Vale la pena añadir que un reproche similar de favorecer a Austria en detrimento de Prusia, Raczyński lo había prensentado ya mucho antes al ministro de Asuntos Extranjeros danés, Hans Krabbe-Carisius. Las quejas de Raczyński, por aquel entonces (en los años 1830-1834) diputado del Reino de Prusia en Copenhague, constituyeron una de las principales causas del creciente conflicto entre Raczyński y el político danés.

${ }^{28}$ «Mr. Donoso Cortès est un homme de rein, un petit avocat de Badajoz, constitutionnel-doctrinaire, grand parleur, à qui cette faculté a valu le sobriquet de quiquiriqui. Il a une vaste érudition, il est auteur. La philosophie de l'histoire est son cheval de bataille. Le ridicule s'est attaché à sa personne», de la carta de A. Raczyński a August Heinrich Hermann von Dönhoff (Rapport politique, n. ${ }^{\circ}$ 37) del 8 de noviembre de 1848, GStA, III, HA Ministerium der auswärtigen Angelegenheiten I, n. 7106. 
Todas estas circunstancias empujaron a Raczyński a emprender actividades diplomáticas oficiales. Durante su encuentro con el ministro Pidal expresó sus dudas y pidió que se frenara el nombramiento de Donoso Cortés durante un par de semanas, plazo necesario para las consultas con Berlín. Hubo en esta actitud de Raczyński una señal visible del juego político (diplomático). En la carta ya anteriormente citada al ministro Dönhoff escribía no sin satisfacción: «Logré, creo, alcanzar dos objetivos siguientes: que el señor Donoso tendrá que esperar y que, en lo que a mí concierne, estoy no solamente disgustado, sino hasta herido ${ }^{29}$.

Solamente un encuentro personal y una conversación prolongada con el español, que se celebró el 17 de noviembre, forzaron a Raczyński a modificar significativamente su opinión y a considerar a Donoso Cortés un comentador perspicaz de la actualidad: «Juzgué que todo lo que decía demostraba una evaluación razonable de los puntos débiles de nuestra época» ${ }^{30}$. La entrevista con Donoso Cortés le tuvo que impresionar profundamente a Raczyński ya que de un día para otro de un escéptico se convirtió en realidad en un partidario y promotor de la persona y del pensamiento del español.

El 7 enero de 1849, Raczyński organizó una cena formal en honor al político español y al día siguiente daba cuenta al rey: «Debo admitir que desde el momento en el que conocí al señor Donoso Cortés, desaparecieron la mayoría de los prejuicios que me han sido inculcados en contra de su persona. Creo que es un hombre razonable, bueno y muy original. Su imaginación es un tanto excéntrica y, si se me permite la palabra, confusa, pero sus talentos son innegables incluso cuando demuestran la naturaleza más sublime que útil $»^{31}$. Para confirmar estas constataciones, el día 18 de enero Raczyński envió a Berlín la traducción francesa del discurso que Donoso Cortés había pronunciado en las Cortes el 4 de enero. Unos días después, el 26 de enero, insertó en la carta a Karl Friedrich von Savigny, amigo y colaborador de su período lisboeta, la

${ }^{29}$ «Je crois avoir obtenu les deux points suivants: c'est que Mr. Donoso attendra, et que personne ne doute que moi pour ma part je suis non seulement mécontent, mais blessé», de la carta de A. Raczyński a August Heinrich Hermann von Dönhoff (Rapport politique, $\mathrm{n}^{\circ}{ }^{\circ}$ 37) del 8 de noviembre de 1848, GStA, III, HA Ministerium der auswärtigen Angelegenheiten I, n. 7106.

${ }^{30}$ «Mr. Donoso Cortes m’a fait hier une longue visite dans laquelle il m’a développé ses vues politiques. J'ai trouvé que tout ce qu'il m'a dit dénotait une appréciation très juste des préoccupation de notre époque», informe de A. Raczyński del 18 de noviembre de 1848, GStA, III, HA Ministerium der auswärtigen Angelegenheiten I, n. 7106.

31 «J'avoue que depuis que j'ai fait connaissance avec Mr. Donoso Cortès, la plupart des préventions, qu'on avait fait naitre chez moi contre lui, ont disparu. Je le crois de très-bonne fait, bon et fort original. Son imagination a bien un peu un caractère excentrique et si j'ose m'exprimer ainsi nébuleux, mais ses talents sont incontestables, quoiqu'ils soient d'un ordre plutôt élevé qu'utile», informe de Raczyński del 8 de enero de 1849 (Rapport politique, n. ${ }^{\circ} 1$ ), GStA, Berlin, III, HA Ministerium der auswärtigen Angelegenheiten I, Madrid, n. ${ }^{0} 7106$. 
siguiente característica del español: «Es muy listo y muy buena gente. Tiene una gran sensibilidad. A veces predomina en él la fantasía, pero incluso entonces guarda un carácter amistoso y fascinante $\rangle^{32}$. Así, el principio del año 1849 marca el inicio de una relación cercana entre estos dos prohombres que, a lo largo de los meses siguientes, ganará en intensidad e importancia hasta llegar a convertirse en una verdadera amistad.

\section{VI}

¿Cuál fue el fundamento de esta amistad? Sobre todo una atrayente similitud de convicciones políticas junto a una cautivadora divergencia de caracteres. Años más tarde, tras la muerte de Donoso Cortés, Raczyński escribirá que Donoso pertenecía a un círculo de amigos muy limitado con quienes le unía una conformidad de opiniones que «excepto con él, no encuentro con nadie»"33. Para entender del todo el significado de estas palabras, hay que presentar brevemente el «credo» político del aristócrata polaco ya que su ideología, a diferencia del pensamiento del español, es muy poco conocida ${ }^{34}$.

Si intentamos reducir la personalidad de Raczyński a unas palabras clave, serían las siguientes: lealtad, monarquismo, posición antidemocrática, orden social y legalidad.

El eje de este programa político es el intento de conservar los elementos nucleares del orden social y político tradicional como una fuerza única capaz de parar el golpe revolucionario que, a su vez, traía, en la opinión de Atanazy Raczyński, injusticia, destrucción, tiranía y guerra. Se trataba del orden social basado en una jerarquía clara y un reparto de papeles transparente: el rey

32 «Er ist sehr geistreich und sehr gut. Er hat viel Gemüth. Die Fantasie geht manchmal durch aber auch denn hat sie einen anziehenden und liebenswürdigen Charakter», de la carta de Raczyński a K. F. von Savigny del 26 de enero de 1849, GStA, VI, HA N1 K.F. v. Savigny - 208: Briefe des Grafen Raczynski an K. F. von Savigny, 1841-1849, 1874. Una característica similar está también en el Diario de Raczyński, escrito ya después de la muerte del español, en 1856 cuando leemos un recuerdo sobre el amigo íntimo (un ami intime) que era un «personnage du reste assez obscure; mais très honnête homme et ancien carliste» (Diario, el 24 de abril de 1856).

${ }_{33}$ Diario, el 8 agosto de 1861.

${ }^{34}$ Raczyński pocas veces hablaba públicamente de temas políticos; publicó de forma anónima sólo un par de artículos en la prensa europea (entre otros un artículo dedicado a la situación política de Inglaterra Les journaux qui attaquent Lord Palmerston..., publicado en la revista de Bruselas Le Nord. Journal quotidien, 3e Année, n. ${ }^{\circ}$ 13, Mardi, 13 Janvier 1857: 1-2). Sus convicciones políticas las puso sobre todo en el Diario con amplios fragmentos tanto dedicados a las normas generales de vida, como a los acontecimientos políticos corrientes que se desarrollaban en Europa. Mientras tanto, muchos estudios se ocuparon del pensamiento político de Donoso Cortés; una bibliografía amplia ha sido preparada por Günther Maschke en: DONOSO CORTÉS, 2007: 430-494. 
soberano concentra en sus manos el poder legislativo y ejecutivo y es apoyado por un grupo privilegiado de gente políticamente consciente que crea una asamblea de consulta. El monarca gobierna a una gran muchedumbre de la población que por su propio bien y en nombre de la paz, del desarrollo armónico y del interés común renuncia - o mejor dicho — es privada de parte de su libertad: no participan en la vida pública y se someten a la voluntad del rey. Este sistema es para Raczyński natural y, como único, estable. Se basa en la naturaleza entendida como el orden sujeto al derecho divino, le droit divin.

Sin embargo, Raczyński se daba perfectamente cuenta de que ante la progresiva secularización de las sociedades y del discurso político, el hecho de recurrir a la instancia transcendental, restaba cada vez más peso a sus argumentos a favor de mantener la estructura tradicional del poder y en contra de las tendencias democráticas de carácter pragmático.

El elemento clave de sus ideas dentro del contexto de la discusión sobre el nuevo orden social lo constituía el postulado de reglamentar la libertad. Limitar la autonomía de las clases bajas de la sociedad servía, según Raczyński, para evitar su ascenso a la posición de sujeto político activo que así inevitablemente llegaría a ser el centro del poder alternativo y opositor frente al monarca $y$, por consiguiente, el portador de un conflicto permanente. Pero si, en cambio, conservamos las estructuras sociales tradicionales que controlan las inclinaciones subversivas, las clases sociales bajas seguirán sirviendo bien al estado y a la sociedad. Las convicciones de Raczyński eran resultado de su idea de que el pueblo tomado en masse, incluso sometido a los procesos formadores, no se quitaría nunca los instintos destructivos desde el punto de vista del estado.

En contra de las masas populares presenta tres principales reproches: la naturaleza del pueblo es, según su opinión, rebelde, difícilmente susceptible a la formación y está centrada únicamente en sus intereses particulares. Además, llama la atención sobre la gran diversificación del pueblo, sobre la presencia en él de personas que carecen de las competencias necesarias para la participación en la vida pública, y sobre su enorme susceptibilidad a la manipulación ${ }^{35}$. Cada una de estas circunstancias tiene unas consecuencias importantes para el programa político de Raczyński y todas ellas, unidas a la desconfianza frente al sistema mayoritario, le obligan a rechazar rotundamente el gobierno representativo (constitucional) de cualquier forma.

Puesto que la sociedad es una estructura heterogénea, agitada por las pasiones y las aspiraciones contradictorias resultantes del egoísmo de grupos o individuos, la confianza en la autenticidad de su voz común, es decir, en la llamada opinión pública, constituye una ficción peligrosa. Para Raczyński, la opinión pública es al mismo tiempo una voz falaz del pueblo y una herramienta que

35 A esa cuestión está dedicada enteramente la carta de Raczyński a Donoso Cortés del 9 de septiembre de 1852, citada en el apéndice.

Hispania, 2019, vol. LXXIX, nº 261, enero-abril, págs. 127-156, ISSN: 0018-2141, e-ISSN: 1988-8368 https://doi.org/10.3989/hispania.2019.005 
sirve para conducir a las masas, utilizada por los ideólogos del movimiento liberal. Sin embargo, se da cuenta de su creciente significado por lo que en varias ocasiones y coherentemente intenta socavar su legalidad y su verosimilitud insistiendo en su inconstancia, inestabilidad y susceptibilidad a la manipulación. En 1848, el año de la crisis, escribía a propósito desde Madrid: «La opinión pública es como el mar: tranquila en su estado natural; inquieta y espumosa cuando los vientos levantan las olas. Cambia sus tonos dependiendo de si la luz celeste la ilumina o esconde sus rayos. Está formado por miríadas de gotas que tienen el mismo color que el que toman prestado de los reflejos de la luz. Es brillante o dulce en reposo, las tormentas lo hacen turbio y negro. Un abismo sin fondo que se llena de fluido infinitamente divisible. Incomprensible, escurridizo, cuyas gotas o fracciones se separan, modifican, fusionan, se convierten en vapor, lluvia benéfica o aguacero, arroyo claro o charco, savia o podredumbre, sangre, sudor, rocío o hielo. Finalmente, todo entra por mil arterias en el reservorio común y se pierde allí: gotas en el mar, opiniones en la inmensidad del movimiento intelectual de la raza humana ${ }^{36}$. Según Raczyński, una presión especial sobre la opinión pública la ejercían los periódicos. Por tanto, consideraba que una censura política eficaz que no abusase de su poder era condición indispensable para mantener los valores más altos: el orden y la paz.

Todas estas premisas conducían a Raczyński a pronunciarse en contra del sistema constitucional representativo y a percibir como alternativa única el sistema monárquico tradicional. A ojos de Raczyński, solamente los gobiernos monárquicos fuertes constituían una fuerza que podría prevenir el fermento revolucionario. Ello no significaba que no hubiese advertido los vicios y las debilidades de los reinados, sin embargo, no veía para ellos ninguna otra alternativa segura: «El poder monárquico es el reino de la tradición, es una marcha lenta, el orden de las cosas menos expuesto al cambio rápido y convulsivo [....]. Los monarcas a veces son repugnantes, los gobiernos representativos siempre lo son $\aleph^{37}$. La realidad contemporánea la percibía en términos de un conflicto inde-

${ }^{36}$ «L'opinion publique est comme la mer: calme dans son état naturel; agitée et se couvrant d'écume quand les vents en soulèvent les vagues. Elle change ses teintes selon que la lumière céleste l'éclaire ou lui retire ses rayons. Elle se compose de myriades de goutes qui n'ont de couleur que celle qu'elles empruntent des reflets de la lumière. Elle est brillante ou suave dans le repos: les tourmentes la rendent trouble, sale, noire. Abyme sans fond que remplit un fluide divisible à l'infini, incompréhensible, insaisissable, dont les goutes ou les fractions se séparent, se modifient, se confondent: deviennent vapeur, pluie bienfaisante ou averse; ruisseau limpide ou mare, sève ou pourriture ; sang, sueur, rosée ou glace. Finalement tout rentre par mille artères dans le réservoir commun et s'y perd: les goutes dans la mer ; les opinions dans l'immensité du mouvement intellectuel du genre humain», Dziennik, 28 de marzo de 1849. Véase también ANTIOCHE, 1880: 10-11.

37 «Le pouvoir monarchique est le règne des traditions, c'est une marche lente, c'est l'ordre des choses qui est le moins exposé aux mutations rapides, aux saccades. [...] Les monarques 
leble entre las fuerzas de la tradición y de la revolución, es decir entre el orden y el caos, el respeto de la ley y la usurpación de la misma, la justicia y el derrame de la sangre, el bien y el mal. A finales del año 1830, marcado por las revoluciones en Francia, Bélgica y Polonia, escribía: «en la situación actual sólo veo una cosa, veo la civilización y el orden social amenazados de muerte, veo a las multitudes lanzadas contra la autoridad, veo todos los eslabones listos para ser rotos, veo que se trata de ser o no ser, y ahora formulo un solo deseo: ver como la civilización se salva de la ruina y como Europa restablece el orden $\rangle^{38}$.

Ya con esta presentación rápida de las ideas políticas de Raczyński se nota que en muchos puntos éstas coinciden con las convicciones de Donoso Cortés. No resulta raro, pues, que su encuentro con el político español - escritor y visionario sugerente - se mostrase muy inspirador para su pensamiento. Puede decirse que los debates personales y por correspondencia que Atanazy Raczyński mantuvo con Donoso dieron a sus ideas políticas el último toque. Adquirió mayor soltura retórica que se expresaba mediante los aforismos lúcidos y las metáforas a menudo acertadas. Más espacio ocupaban en ellas las consideraciones de naturaleza política general o, incluso, de filosofía de la historia. Por ende, Raczyński algunos de sus motivos importantes los tomó directamente de los conceptos del español, entrelazándolos con su propia teoría política.

En la ya citada carta a Karl Friedrich von Savigny de principios de 1849, escribía: «Mis posturas políticas cambiaron hasta tal punto que ahora ya no creo que el absolutismo sea un medio suficiente. Mientras los demagogos no sean domesticados, sólo le regime du sabre [el régimen del sable] puede proteger a la sociedad. Después se podrá volver a las formas posiblemente liberales del absolutismo prusiano y la burocracia, pero aún estamos lejos de estar maduros para eso» ${ }^{39}$. La convicción de que el absolutismo resultaba harto débil frente al peligro mortal que venía de mano de los portadores de la revolución: ateístas, liberales y socialistas, provenía — igual que el concepto del «régimen del sable»— directamente

sont quelque fois détestables, les gouvernements représentatifs le sont toujours», Dziennik, 27 de diciembre de 1836.

38 «dans l'état présente des affaires je ne vois qu'une chose, je vois la civilisation et l'ordre social menacés de la mort, je vois les multitudes lancées contre les autorité, tous les liens prêts à se briser, je vois qu'il est question d'être ou de ne pas être, et je ne forme maintenant qu'un seul voue, c'est de voir la civilisation sauvé de la ruine et l'Europe recouvrer l'ordre». De la carta de A. Raczyński al ministro prusiano del exterior Heinrich Werther del 18 de diciembre de 1830, Politisches Archiv des Auswärtigen Amtes, Berlin, Acta betr. die persönlichen Angelegenheiten des Grafen von Raczinsky, 011609.

39 «Meine politische Gesinnungen haben sich dahin geädert als ich jetzt den Absolutismus nicht mehr für zureichend erachte. Solange die Demagogen nicht gezähmt sind, kann nur le regime du sabre die Gesellschaft schützen. Später wird man zur möglichst liberalen Form der preußischen Absolutismus und der Bureaucratie zurückkehren dürfen, dafür sind wir aber jetzt noch lange nicht reif», de la carta de a K. F. von Savigny del 26 de enero de 1849, GStA, VI, HA N1 K.F. v. Savigny - 208: Briefe des Grafen Raczynski an K. F. von Savigny, 1841-1849, 1874. 
de los conceptos de Donoso Cortés. El «régimen del sable» es un sinónimo del concepto de la dictadura que Cortés, mediante el Discurso sobre la Dictadura, introdujo en el debate político moderno ${ }^{40}$. En su famosa frase cerró de forma escueta la quintaesencia de su idea: «Cuando la legalidad basta para salvar la sociedad, la legalidad, cuando no basta, la dictadura». Donoso Cortés y, luego, siguiéndole Raczyński, no tenían dudas: la legalidad no era suficiente para salvar a la sociedad. A «la tiranía y despotismo desenfrenado» de las masas revueltas, a la «dictadura del puñal y de la gentuza», solo podía contestarse con la dictadura política del orden respaldada por la legitimidad divina, el «régimen del sable» ${ }^{41}$.

Al igual que Donoso, Raczyński estaba convencido de que sólo podía tener éxito con el uso de la fuerza y a expensas de las víctimas: ambos consideraban inevitable la guerra universal. «La guerra saldrá del seno de la situación [...], la guerra es necesaria», escribió el español; «Sí, ciertamente saldrá y puede ser fatal, ciertamente terrible, pero no se puede evitar», contestaba Raczyńskit ${ }^{42}$. Sin embargo, estaban discutiendo entre ellos sobre su decisión final: el providencialista Raczyński no podía aceptar la visión radical y fatalista de su amigo español. Sí, también reconoció la presencia real de Satanás y su causalidad en la historia pero no dudó de la victoria final de la Divina Providencia: «Tengo fe en el futuro porque Dios visiblemente protege a la sociedad», escribió en 1852. $\mathrm{Y}$ en otro lugar, en referencia directa a las convicciones de Donoso: «Su razonamiento es lógico y se basa en el conocimiento de las personas, de los acontecimientos pasados, de los detalles, de los hechos, mientras que yo cuento con lo imprevisible y con la Providencia, que desde hace cuatro años protege constantemente a la sociedad y condena la demagogia» ${ }^{43}$.

\section{VII}

Hubo, sin embargo, otra circunstancia que en Raczyński despertaba la simpatía y la admiración hacia Donoso. Fue el carácter, un tanto excéntrico, del

40 Discurso sobre la Dictadura había sido pronunciado en las Cortes el 4 de enero de 1849 apenas tres semanas antes de la carta de Raczyński citada.

${ }^{41}$ Sobre el complejo concepto de dictadura en Donoso Cortés véase: SCHRAMM, 1935: 66-75. BENEYTO, 1988. SPEKTOROWSKI, 2002: 294-298. MASCHKE, 2007: XXVIII-XXXI.

${ }_{42}$ «La guerra saldrá del seno de la situación, a pesar de la voluntad de los hombres: la guerra es necesaria. Oui, sans doute saldré et elle sera peut-être funeste, bien sûr terrible; mais elle ne peurra êtra évitée», de la carta de Raczyński a Donoso Cortés del 3 de marzo de 1852, copia en Dziennik.

43 «Vos raisonnements sont logiques et basés sur la connaissance que vous avez des hommes, des antécédents, des intérêts particuliers, des faits; mais moi, je compte sur l'imprévu et sur la providence qui depuis quatre ans n'a pas cessé de protéger la société et de fustiger la démagogie», de la carta de Raczyński a Donoso Cortés del 21 de abril de 1852, copia en Dziennik. 
español, su «espíritu como volcán y su imaginación que no conoce descanso» ${ }^{44}$. Raczyński, maduro, razonable, experimentado, con verdadero interés observaba a Donoso Cortés, perteneciente a la generación posterior, y se comparaba con ese hombre cuyo talento - y Atanazy lo reconoció perfectamente- iba a desarrollarse plenamente. Donoso estaba en el umbral de la gran fama europea. Los dramáticos acontecimientos revolucionarios de los años 1848-49 dieron a su pensamiento un nuevo rumbo y una nueva potencia, que permitieron hacer brillar plenamente su intelecto perspicaz y su retórica visionaria, y confirieron a sus textos una actualidad excepcional y la condición de manifiestos antirrevolu$\operatorname{cionarios}^{45}$. En pocos años, justamente en los que mantuvo su amistad con Raczyński, Donoso Cortés elaboró o condujo a la madurez los conceptos que lo convirtieron en uno de los intelectuales más refinados y en uno de los representantes más destacados del pensamiento reaccionario europeo: idea de la desacralización del mundo y la crisis progresiva de la religiosidad ergo de la civilización que iba a conducir a consecuencias catastróficas; idea del conflicto, inevitable y definitivo, entre la civilización «católica» y la «filosófica»; de la venidera alianza mortal de los liberales con los socialistas; de la dictadura como única forma posible de defensa ante la tiranía de las masas revueltas. Y profesaba dichas ideas con excepcional soltura, a menudo sin medir palabras.

Para Raczyński las conversaciones con Donoso Cortés - las personales, primero en Madrid y, posteriormente, en abril de 1851 en Bruselas o en agosto de 1851 y septiembre de 1852 en París, y en particular el intercambio de cartassupusieron una provocación continua, un reto intelectual sin un momento de descanso. Las diatribas del español —impiadosas y exageradas - dirigidas contra la naturaleza humana y sus visiones apocalípticas del porvenir de Europa ${ }^{46}$ excedían con creces las ideas pesimistas de Atanazy. La crítica profunda e intransigente de Prusia y de su monarca Federico Guillermo $\mathrm{IV}^{47}$, supuso por su parte un reto para la conciencia de Raczyński, un funcionario prusiano de alto rango quien en Prusia y en su rey deseaba ver el cumplimiento de sus ideales políticos y sociales.

El conde Adhémar d'Antioche, en la introducción a la mencionada edición de la correspondencia entre Donoso y Raczyński, de forma brillante y acertada describió la relación que los unía, indicando la intrigante disconformidad de sus caracteres: «Pero si el marqués de Valdegamas tenía muchos puntos de vista comunes en la política con el conde Raczyński, se diferenciaba de él en

${ }_{44}$ «Votre âme est en volcan et votre imagination ne connaitra jamais le repos», de la carta de Raczyński a Donoso Cortés del 29 de septiembre de 1851, copia en Dziennik. Véase también la característica del pensador español en su carta del 9 de noviembre del mismo año, citada en el apéndice.

45 ACEDO CASTILLA, 1956. BENEYTO, 1988: 56.

46 SCHMITT, 2009: 28-30, 70-72.

47 ANTIOCHE, 1880: 306. SCHMITT, 2009: 49-57.

Hispania, 2019, vol. LXXIX, nº 261, enero-abril, págs. 127-156, ISSN: 0018-2141, e-ISSN: 1988-8368 https://doi.org/10.3989/hispania.2019.005 
más de un aspecto: en el primero, siempre encontramos imaginación, poesía, no sé qué acento lleno de ternura, sentimiento y encanto. Me atrevería a decir que la naturaleza del conde Raczyński es todo lo contrario: la nitidez y el vigor son los rasgos más característicos de la misma. Se descubren en él muchas cualidades francesas que no afectan a Donoso Cortés: finura, nitidez de estilo, precisión de pensamiento, originalidad de expresión, arte de razonar. En el primero, hay una asociación de dones seductores, mientras que la habilidad, la ciencia y la fuerza son prerrogativa del segundo; uno atrae y seduce, el otro inspira la idea de superioridad, ejerce el ascendente del talento. Ambos son sinceros y desinteresados, y también merecen respeto $\rangle^{48}$.

El propio Raczyński, años después, indicó los rasgos de personalidad de Donoso como más atractivos que sus valores intelectuales. En una carta dirigida a otro amigo diplomático, el conde Alphonse de Brotta Antioche, caracterizó al español del siguiente modo: «Había algo en este hombre que aún sobrepasaba su inteligencia que era tan poderosa: la amabilidad de su carácter, la bondad de su corazón, su veracidad, su horror a los malos principios. Sólo conocía en él dos defectos: la vanidad y debilidad de sus nervios. Lo reducían y a veces le hacían parecer un niño. ¡Pero qué buen niño! ¡Y cuán divinamente inspirado estaba este niño! Le amaba con pasión. Es para mí un motivo de gloria el que siempre me haya mostrado tanta confianza y simpatía» ${ }^{49}$. Escribió estas palabras casi diez años después de la muerte de Donoso Cortés producida en París el día 8 de mayo de 1853, a la edad de tan solo 44 años. Raczyński vivió veinte años más y murió en Berlín el 21 de agosto de 1874.

\section{APÉNDICE: Cartas de Atanazy Raczyński a Juan Donoso Cortés, según las copias incluidas en Dziennik}

\section{9 de noviembre de 1851, Dziennik, t. VII: 197-203, no publicada.}

Madrid le 9 de Novembre 1851

Mon très-cher Marquis, il y a toujours joie et jubilation à la Légation de Prusse cuando llega una carta de V.E.

48 ANTIOCHE, 1880: XXXI-XXXII.

49 «Je viens de relire un discours de Valdegamas de l'année 1850. C'est, en vérité, la prophétie la plus miraculeuse. J'y avait chez cet homme quelque chose qui surpassait encore son intelligence qui était si puissant: c'était l'amabilité de son caractère, la bonté de son coeur, sa véracité, son horreur des mauvais principes. Je ne lui connaissais que deux défauts: c'était la vanité et la faiblesse de ses nerfs. Cela le rapetissait et le faisait quelques fois paraitre un enfant. Mais, quel bien enfant! et comme cet enfant était divinement inspiré! Je l'aimais avec passion. Je regarde comme en titre de gloire qu'il m'ait toujours montrés tant de confiance et de sympathie», de la carta de A. Raczyński a Alphonse d'Antioche del 15 de marzo de 1861, copia en Dziennik. 
Je sais positivement que quelqu'un a reçu ici la nouvelle du retour prochain de Narvaez. Celui qui a écrit cela, sait ce qui en est, mais il a pu avoir de bonnes raisons pour dire le contraire de la vérité, aussi je crois plutôt, à ce que vous me dites dans votre lettre du 2, et en effet, il me semble qu'il ferait mieux de ne pas venir.

Je voudrais bien, mais je n'ose pas vous faire part de ce que j'ai écrit à mon Gouvernement sur vous et sur la crainte que vous inspirez à ceux qui par nature, par des vues intéressées ou par préoccupation, craignent de vous voir prendre une part plus directe et plus grande aux affaires de ce pays-ci. N'auriez-vous pas déjà reçu une indication analogue?...

$\mathrm{Si}$, tôt ou tard, vous revenez ici, rappelez-moi cette circonstance: je vous en fournirai l'explication. Ce symptôme d'une opposition très-forte contre vous est dans la nature des choses: elle n'a rien qui doive me surprendre, elle me comble de joie, car elle me prouve que je vous ai bien jugé et que vous êtes nécessaire. Quand les loups portent plainte contre un chien, c'est que le chien est un bon gardien. Votre temps ne tardera pas j'espère à venir et l'Europe et les peuples ne s'en trouveront pas mal.

Quoique je sois un enfant très-impressionnable et très capable de m'engouer, ne croyez pas que je vous prenne aussi pour un enfant ou pour une colombe. Il $\mathrm{y}$ avait un temps où je vous croyais seulement fort intéressant et fort attachant, où vous me charmiez et où je me sentais attiré vers vous instinctivement; mais ce n'est pas de hier que je me suis aperçu que, quoique vous ayez une prodigieuse imagination et originalité dans les formes, votre bon cœur fait très bon ménage avec votre prudence, vos principes avec les nécessités et vos soudaines inspirations avec votre sage persévérance. Je ne crains pas que vous soyez la dupe de personne: pas même de la plus profonde immoralité, des élans de générosité vrais ou joués, de l'audace, de l'astuce, de l'ambition la plus effrénée, de l'avidité la plus insatiable.

Je félicité la bonne cause et je me félicite de ce que vous abandonniez vos succès de tribune; car cela me prouve que la tribune devient faible pour faire le bien et que vous espérez faire mieux qu'impressionner le public et cueillir cette sorte de lauriers.

Je suis de votre avis sur un point: c'est que le soi-disant parti de l'ordre est le désordre incarné. Il ne se compose en effet que de confusion, de mille nuances des doctrines voltairiennes, de préoccupations, de préjugés et d'aberrations. Ce parti une fois vaincu par le Président ${ }^{50}$, par Changarnier ${ }^{51}$, par le socialisme ou par le Diable, la vraie monarchie deviendra, comme vous dites,

${ }^{50}$ Luis Napoleón Bonaparte (1808-1873), presidente de la Segunda República Francesa y posteriormente, desde 1852, emperador de los franceses con el nombre de Napoleón III.

${ }^{51}$ Nicolas Changarnier (1793-1793), militar francés, relacionado con el partido monárquico, partidario de la Casa de Orleans. 
possible. Jusque-là nous sommes d'accord; mais ces trois victoires n'ont point à mes yeux la même valeur. Je ne place pas sur la même ligne le président avec Changarnier et encore moins ces deux messieurs avec le socialisme et le diable.

Il est possible que le Président, après avoir vaincu le soi-disant parti de l'ordre, parvienne à dompter momentanément le socialisme; mais je doute qu'il puisse - à cause de son origine, de son entourage et de son essence- extirper la révolution intégralement. Le Président est tout au plus une comète. Je suis plus disposé à croire qu'il n'est pas du tout un corps céleste. Mais en attendant, il faudrait rester l'arme au bras, pour voir si cette énormité politique devient une véritable solution, et en attendant, l'Empereur Nicolas ${ }^{52}$, qui a 55 ans, s'approchera du terme de sa carrière. Je préférais Changarnier au Président, car il est possible et même probable que Changarnier aurait assez d'esprit et assez d'honorabilité pour vouloir remettre sur le trône Henri V, qui, sans la Charte et jouissant de la confiance et des sympathies de tous les Gouvernements, hors un seul, pourrait seul clore l'inventaire de toutes les péripéties révolutionnaires. J'aimerais donc mieux Changarnier que le Président; mais je préfère de beaucoup et par-dessus tout la troisième éventualité: le triomphe du socialisme et du diable - qui au fond ne font qu'un - car il me paraît presque sûr que le socialisme ne tardera pas à amener l'anarchie en France et la guerre chez nous. Il faut se battre; il n'y a pas de remède. Tout le reste est du replâtrage.

Ici le niño s'arrête, car la colombe se dira le reste.

Il faut se battre, je ne sors pas de là. Le plus tôt sera le mieux. Nous pourrons perdre des batailles, mais si on n'écrase pas le libéralisme, la société ne peut échapper à la dissolution.

Je sais qu'à la Cour on fait grand cas de Lord Howden ${ }^{53}$, on dit du bien de moi, mais on éprouve peu de sympathies pour Esterhazy ${ }^{54}$. J'en suis fâché, car j'ai de l'amitié pour lui et il a des qualités estimables. Il ne sait souvent pas ce qu'il dit, il s'emporte, il blesse et il s'est fait ainsi beaucoup d'ennemis. Je n'ose lui faire d'observations, car je crains de blesser son amour propre.

On dit depuis longtemps que cette session sera orageuse, scandaleuse et factieuse, et en effet cela en prend la tournure. La majorité ministérielle est grande, mais qu'est-ce que cela prouve? Je suis curieux, si dans ce moment-ci $\mathrm{Mr}$. Bertrand de Lis $^{55}$ est enchanté du système parlementaire. Cependant je suis convaincu qu'il ne songe pas à faire divorce avec lui, car ce n'est que ce système

\footnotetext{
${ }^{52}$ Nicolás I Romanov (1796-1855), desde 1825 zar de Rusia.

53 John Hobart Caradoc, segundo Lord Howden (1799-1873), diplomático británico, entre 1850 y 1858 ministro plenipotenciario en Madrid.

${ }^{54}$ György Esterhazy de Galántha (1809-1856), aristócrata y diplomático húngaro, desde 1847 enviado a Madrid.

${ }_{55}$ Manuel Bertrán de Lis y Ribes (1806-1869), político español, entre 1851 y 1852 ministro de Asuntos Exteriores.
} 
qui pourra le ramener au pouvoir et en faveur de cette éventualité, il lui pardonnera toujours de le renverser. C'est là le secret du constitutionnalisme de presque tous les hommes d'état sortis des révolutions.

En voilà assez pour aujourd'hui, je vais lire l'Univers. Je vous embrasse tendrement.

Je vous parlerai une autre fois de votre cuisinier. Puisqu'il est bon, faites-lui mes compliments. Les bons cuisiniers sont conservateurs; les mauvais produisent des révolutions, des vents, des tourmentes et des cataclysmes. Je suis sûr qu'il guérira votre ventre.

\section{7 de febrero de 1852, Dziennik, t. VII: 310-316, no publicada.}

\section{Madrid le 27 Févier 1852}

Votre lettre du 18 m'a donné à penser. La réaction libérale et la pression (non le triomphe) de l'Angleterre se font ici sentir fortement, mais rien chez vous n'est définitif; car vous n'êtes pas indépendants, ni forts: vous n'êtes pas encore: vous le serez, j'espère, si la cause de l'ordre triomphe: vous le serez par la force des choses, quand la lutte s'engagera. Je vous souhaite une organisation et une conformation qui fasse de vous une puissance libre dans ses mouvements. Je vous souhaite cette liberté, car elle ne peut que devenir utile à vous et à la cause de l'ordre. La question ne se décidera cependant que lorsque la politique du Président se sera dessinée d'une manière claire. S'il s'entend avec les Anglais, il n'y a rien à espérer pour vous et l'Europe courra de grands dangers, s'il s'entend avec nous la cause pourra être gagnée. Si vous êtes émancipés de la France, celle-ci y gagnera encore, si en même temps vous êtes émancipés de l'Angleterre, car jusqu'ici tout ce que la France a pu obtenir de votre faiblesse, c'est de flotter entre elle et l'Angleterre. La France n'a jamais menacé l'Angleterre ni même Gibraltar, quelque chose qu'elle ait pu entreprendre par ses armées, par ses mariages et ses ingérences; tandis que les Anglais, après avoir pris poste sur le territoire Espagnol, ont bien su passer Pyrénées et savent très-bien alimenter désordre d'idées dont la contagion se propage sans cesse. Le France ne peut craindre que vous soyez forts, car assurément, elle ne peut pas vouloir vous arracher des provinces et vous, de votre côté vous ne pouvez pas songer à vous étendre au-delà de Pyrénées.

Passons à la faute (le décret de confiscation ${ }^{56}$ ). J'y ai cru instinctivement: je n'y crois plus. Le coup était hardi, imprévu, nouveau, j'en ai été abasourdi. Après y avoir réfléchi, je ne vois plus dans cette mesure qu'un fait insignifiant. Que le président se proclame Empereur, et il ne sera plus question des pétards,

\footnotetext{
${ }^{56}$ Se trata del decreto de Luis Napoleón del 10 de enero de 1852 relativo a la confiscación de los bienes de la Casa de Orleans.
} 
partis à cette occasion des salons de Paris. J'ai honte de m'en être et je vois seulement que je ne suis pas toujours à la hauteur des circonstances. Ce serait en vain que le président chercherait à plaire à ceux qui maintenant sont à la sape. Il aurait aussi tort de faire des contremines: son auxiliaire est à l'intérieur la force. Qu'il se fasse dis-je, Empereur! On m'objectera que le nom ne fait rien à la chose et que la chose existe. Pas du tout: cela fait beaucoup. Les populations laborieuses demandent un maître elles croiraient bien mieux le tenir, si ce maître s'appelait Empereur, l'armée demande un chef qui se dessine fortement et cet emblème produirait cet effet. Au reste admettons qu'il ait fait une faute. Qu'y a-t-il d'étonnant? Je voudrais voir qui n'en fait pas, et surtout quand la position est difficile. Or la sienne est une des plus difficiles qui n'ait jamais existé depuis le commencement du monde. Ce que je crains, c'est qu'il ne se fasse Anglais dans l'intérêt supposé de son pouvoir et de l'agrandissement de la France; qu'il ne livre, qu'il ne vende le reste de l'Europe aux Anglais. Alors vraiment l'Angleterre deviendrait la maîtresse du monde jusqu'à ce qu'elle ne périsse par les influences qu'elle a déchaînées contre l'Europe. Ce serait alors en vérité la dissolution de la société européenne.

Il me reste encore un sujet à traiter: c'est l'alliance du Nord. Vous dites que les hommes d'état manquent à notre époque. Ce que je crois-moi, c'est que la situation est tellement difficile que les plus grandes capacités ont de la peine à se tirer d'affaire. J'ai une haute opinion de Manteuffel $^{57}$ et je crois que la conduite du Cabinet de Petersburg est sage et forte. Je crois aussi que l'Angleterre a fait tout ce qu'elle devait faire pour retarder sa ruine. Ainsi tout le monde n'est pas bête et jusqu'ici le Président a été habile, fort habile, excessivement habile. Nous verrons plus tard s'il continue à l'être.

Le Prince Schwarzenberg ${ }^{58}$ fait tout ce qu'il peut par forcer la Prusse à chercher un appui ailleurs, mais j'espère qu'il ne parviendra pas à nous faire faire fausse route. Dieu donne seulement qui l'Empereur Nicolas reste à la tête d'alliance! Si le ciel nous la conserve, j'espère que l'alliance Nord, qui renferme les éléments les plus précieux de notre salut à tous, sera conservée, et que la France s'unira à nous pour abattre la démagogie et pour ôter à l'Angleterre les moyens de nous ruiner tous: physiquement et moralement.

En 1848 je croyais tout perdu, maintenant je suis loin de désespérer du salut de la société. Que de triomphes ont été remportés, que de difficultés vaincues! Dieu semble avoir prononcé ces paroles «vous n'irez pas plus loin» et la démagogie fait de vains efforts pour briser les chaînes qui l'étreignent et l'écrasent.

57 Otto Theodor von Manteuffel (1805-1882), político prusiano, entre 1850 y 1858 ministro de Asuntos Exteriores.

${ }^{58}$ Felix zu Schwarzenberg (1800-1852), político austriaco, entre 1848 y 1852 primer ministro y ministro de Asuntos Exteriores. 
Je ne concevrais pas qu'on ne vous aimât point, ainsi, il ne m'est pas difficile de comprendre que vous charmez, que vous inspirez des sympathies de la confiance et de l'estime. Ce que je sais surtout, c'est que je vous suis sincèrement attaché.

Le Comte Antioche ${ }^{59}$ vous remettra plusieurs volumes d'un ouvrage de Louis Blanc. Je vous prie de me les envoyer par courrier: deux à deux ou trois à trois: comme vous pourrez.

La société du Comte Antioche m'a été fort agréable. C'est un homme de tête et ses manières sont parfaitement distinguées et aimables. Quant à ses principes politiques: je puis seulement vous dire qu'il m'en a montré de bons. Est-il dissimulé, est-il à droit ou bien est-il incertain? C'est ce que je ne saurais vous dire.

Maintenant encore quelques mots sur ce pays-ci.

Isturiz remet son départ d'un jour à l'autre. Je ne sais ce que je dois en penser. Les brouilles et les raccommodements au Palais se succèdent sans cesse. Je ne sais si Bravo Murillo est fort, ou s'il est sur le bord du précipice: je m'y perds. J'ai peu de confiance dans l'armée: c'est à dire dans l'infanterie. Les autres corps sous Azpiroz, Ahumada, Shelly sont bons. Le corps de génie n'est plus aussi sûr qu'il le fût.

L'Anglais a de l'influence, mais surtout il veut en avoir l'air. Sa vanité le perdra. Il est fin, mais il a fini par se faire connaître et à cour on le juge sévèrement. Il n'y a que le Roi qui en soit enchanté, mais l'influence u Roi est devenue nulle.

Je voudrais savoir, si quand je vous écris une si longue lettre, vous vous donnez la peine de la lire. Mais ne vous gênez pas, cher ami, je fais quelquefois copier les lettres que je vous écris dans mon journal, et alors elles ne sont pas perdues pour moi: ce sont des souvenirs que j'aime à conserver; d'ailleurs, c'est comme si je n'entretenais avec vous et cela me fait toujours plaisir, parce que je vous aime.

J'ai peine à croire que le parti libéral soit vaincu en Angleterre par l'entrée -peut-être très précaire de Lord Derby ${ }^{60}$ au Ministère.

\section{9 de septiembre de 1852, Dziennik, t. VII: 496-499, no publicada.}

\section{Paris le 9 Septembre 1852}

Mon cher Marquis, je vous propose une correspondance destinée à devenir livre. Prenez cette proposition comme de la modestie de ma part, car je sais très bien qu'à côté de vous je paraitrai pâle et faible.

${ }^{59}$ Charles-François-Alphonse de Brotty d'Antioche (1813-1882), diplomático saboyano, ministro delegado del Reino de Saboya y Cerdeña en Madrid.

${ }^{60}$ Edward Geoffrey Smith Stanley, 14 Conde de Derby (1799-1879), político británico conservador, de febrero a diciembre de 1852 primer ministro de un gobierno minoritario. 
Rétablir le sens des mots: voilà ce que je vous propose et ce que je me propose à moi-même.

La confusion des idées trouve sa source - peut-être exclusivement- dans le faux emploi des mots. Des spirituels, mais infâmes écrivains ont formé ce salmigondis que n'ont cessé de mâcher depuis les meilleurs esprits.

Les hommes, le peuple, sont des mots que tout le monde en politique emploie de la manière la plus fausse.

Savez-vous pourquoi les hommes doivent obéir? C'est qu'ils ne peuvent commander. Un homme peut commander; les hommes ne peuvent que se disputer ou obéir. Personne ne veut obéir parce que chacun veut commander. Chacun se range dans la multitude pour protester contre l'autorité; mais c'est pour s'en isoler quand il saisit le pouvoir ou une partie du pouvoir.

On est tellement accoutumé, dans le langage commun, à dire, le peuple veut, pense, gémit, soupire, que je ne serais pas étonné, si moi aussi dans ce travail que je vous propose et qui serait destiné à mettre fin aux inconvénients que je signale... Si moi-même dis-je, je tombais dans la même faute; mais je tâcherai de l'éviter.

Ce que je cherche, c'est de soustraire la société à tous les égarements qui résultent pour elle du faux emploi des mots collectif peuple, opinion publique, société, démocratie, aristocratie, les honnêtes gens, la presse, les gueux, les royalistes, les libéraux, les républicains, etc. etc., toutes les fois qu'on veut faire de ces mots collectifs autre chose qu'une notion. Tous ces mots, qui peuvent aussi être traduits par tout le monde, pêle-mêle, on, sont bons, mais ils ne sont pas bons à toute sauce.

Il y a des gueux, il y a des honnêtes gens, il y a une presse, etc., etc., mais collectivement, comme catégorie agissante, pensante, on ne sait où cela commence et où cela finit, ce que cela veut, ce que cela fera. C'est à dire que dans ce sens, collectivement, on ne sait ce que cela signifie, ce que cela est.

Aussitôt qu'une multitude de gens, placée dans une de ces catégories, agit, celle ne peut plus agir que pat boutade, entrainement, peur; et chaque individu, excepté celui qui entraine les autres, devient mouton, et il est mouton, soit qu'il se montre soumis, soit que pour s'abuser soi-même et les autres, il se montre furieux.

Si le mauvais emploi des mots collectifs peuple, opinion publique, \&c. est un mal incommensurable, combien ce danger devient plus palpable si nous nous arrêtons au mot de liberté.

Enfin, vous comprenez ce que je vous propose. Voyez si cela vous convient.

Quel service ne rendrait-on pas à la société, si on disait hautement sur les serments politiques, ce qu'il y a eu dire: c'est à dire que ces serments sont à tout jamais prostitués, profanés, sans force, et sans valeur! Admettez la sainteté des serments, extorqués par le libéralisme et les révolutions, et tout est dit: il ne faut plus songer à combattre le mal. On ne s'en tirera pas avec des subtilités.

Hispania, 2019, vol. LXXIX, nº 261, enero-abril, págs. 127-156, ISSN: 0018-2141, e-ISSN: 1988-8368

https://doi.org/10.3989/hispania.2019.005 


\section{Bibliografía}

Acedo Castilla, José Francisco, Donoso Cortés y la Revolución del 1848, Sevilla, Sección de Crónicas y Publicaciones del Excmo. Ateneo de Sevilla, 1956.

Antioche, Adhémar d', Deux diplomates le comte Raczynski et Donoso Cortés marquis de Valdegamas. Dépêches et correspondence politique 1848-1853, Publiées et mises en ordre par le comte Adhémar d'Antioche, París, E. Plon, 1880.

Antioche, Adhémar d', «Le dernier hiver d'un règne. París, 1824. Impressions d'un témoin», Revue d'histoire diplomatique publiée par les soins de la Société d'Histoire Diplomatique, Dix-septième année (París, 1893): 124-147.

Beneyto, José María, Apokalypse der Moderne. Die Diktaturtheorie von Donoso Cortés, Stuttgart, Klett-Cotta, 1988. Sprache und Geschichte, 14.

Bled, Jean-Pierre, «Donoso Cortés, ambassadeur en Prusse (février 1849-novembre 1849)», L’information historique, 35\% 5 (París, 1973): 209-216.

Börsch-Supan, Helmut, «Die Geschichte der neueren deutschen Kunst von Athanasius Graf Raczyńsk», en Wulf Schadendorf (Hg.), Beiträge zur Rezeption der Kunst des 19. und 20. Jahrhunderts, München, Prestel, 1975: 15-26.

Büttner, Frank, «Athanasius Graf Raczyński als Apologet der Kunst seiner Zeit», en Konstanty Kalinowski und Christoph Heilmann (Hg.), Sammlung Graf Raczyński. Malerei der Spätromantik aus dem Nationalmuseum Poznań, München, Hirmer, 1992: 45-60.

Danilewicz Zielińska, Maria, «Atanásio Raczynski, 1788-1874. Um historiador de arte portuguesa», Belas-Artes. Revista e Boletim de Academia Nacional de Belas-Artes, 3a Série/3 (Lisboa, 1981): 51-70.

Deswarte-Rosa, Sylvie, «Athanase Raczynski au Portugal, 1842-1848. Luz e Sombra», Artis. Revista do Instituto de História da Arte da Faculdade de Letras de Lisboa, 9/10 (Lisboa, 2010-2011): 19-91.

Donop, Lionel von, «Raczynski, Athanasius Graf», en Allgemeine Deutsche Biographie, 1888, onlinefassung, URL: http://www.deutsche-biographie.de/pnd118743406. html.

Donoso Cortés, Juan, Obras de Don Juan Donoso Cortés marqués de Valdegamas. Nueva edición aumentada con importantes escritos inéditos y varios documentos relativos al mismo autor, publicado por su Hermano Don Manuel bajo la dirección y con un prólogo de Don Juan Manuel Ortí y Lara, Madrid, Editorial de San Francisco de Sales, 1904, vol. II: 637-645.

Donoso Cortés, Juan, Essay über den Katholizismus, den Liberalismus und den Sozialismus und andere Schriften aus den Jahren 1851 bis 1853, herausgegeben, übersetzt und kommentiert von Günther Maschke, Wien und Leipzig, Akademie-Verlag, 2007.

Falkowski, Juliusz, Obrazy z życia kilku ostatnich pokoleń w Polsce, Poznań, Jan Konstanty Żupański, 1882, vol. II.

Gaehtgens, Thomas W., «Französische Historien- und deutsche Geschichtsmalerei. Über den Besuch des Grafen Raczynski im Salon von 1836», en Dieter Hein, Klaus Hildebrand y Andreas Schulz (Hg.), Historie und Leben. Der Historiker als Wissenschaftler und Zeitgenosse. Festschrift für Lothar Gall zum 70. Geburtstag, München, Oldenbourg, 2006: 257-271. 
Grauer, Elise F., «Briging the Gap, Count Athanazy Raczyński and His Galleries in Poland and Prussia», Artium Quaestiones, XV (Poznań, 2004): 5-49.

Grypa, Dietmar, Der Diplomatische Dienst des Königreichs Preußen (1815-1866). Institutioneller Aufbau und soziale Zusammensetzung, Berlin, Duncker \& Humblot, 2008. Quellen und Forschungen zur Brandenburgischen und Preußischen Geschichte, 37.

Kaiser, Uta, Sammler, Kenner, Kunstschriftsteller. Studien zur «Geschichte der neueren deutschen Kunst» (1836-1841) des Athanasius Graf Raczynski, Hildesheim, Olms, 2017.

Kieniewicz, Stefan, «Raczyński Atanazy (1788-1874)», en Wrocław et al., Polski Słownik Biograficzny, Krakow, Wroclaw Zakład Narodowy im. Ossolińskich, 1986, vol. XXIX: 625-627.

Labuda, Adam S., Mencfel, Michał y Suchocki, Wojciech (red.), Edward i Atanazy Raczyńscy. Dzieła - osobowości - wybory - epoka, Poznań, Muzeum Narodowe w Poznaniu, 2010.

Maschke, Günther, «Endzeit, Zeitende. Zum Spätwerk von Juan Donoso Cortés», en Juan Donoso Cortés, Essay über den Katholizismus, den Liberalismus und den Sozialismus und andere Schriften aus den Jahren 1851 bis 1853, Wien und Leipzig, Akademie-Verlag, 2007: XII-LI.

Mencfel, Michał, Atanazy Raczyński (1788-1784). Biografia, Poznań, Wydawnictwo Naukowe UAM, 2016.

Raczyński, Athanase, Les arts en Portugal. Lettres adressées à la Société artistique et scientifique de Berlin, et accompagnées de documens, París, J. Renouard, 1846.

Raczyński, Athanasius, Noch ist Polen nicht verloren. Aus den Tagebüchern des Athanasius Raczyński 1788 bis 1818, herasugegeben und übersetzt von Joseph A. Graf Raczyński, Berlin, Siedler, 1984.

Schmitt, Carl, Donoso Cortés in gesamteuropäischer Interpretation. Vier Aufsätze, Berlin, Duncker \& Humblot, 2009.

Schramm, Edmund, Donoso Cortés. Leben und Werk eines spanischen Antiliberalen, Hamburg, Ibero-Amerikanisches Institut, 1935. Ibero-Amerikanische Studien Bd. 7.

Spektorowski, Alberto, «Maistre, Donoso Cortés, and the Legacy of Catholic Authoritarianism», Journal of the History of Ideas, 63/2 (Philadelphia, 2002): 283-302.

Recibido: 02/01/2018

Aceptado: 18/02/2019

Hispania, 2019, vol. LXXIX, n 261, enero-abril, págs. 127-156, ISSN: 0018-2141, e-ISSN: 1988-8368

https://doi.org/10.3989/hispania.2019.005 